\title{
Fluorescent and Electroactive Monoalkyl BTD-Based Liquid Crystals with Tunable Self-Assembling and Electronic Properties
}

\author{
Marcelo Echeverri, ${ }^{\dagger}$ Irene Martín, ${ }^{\dagger}$ Alberto Concellón, ${ }^{\ddagger}{ }^{+0}$ Constanza Ruiz, ${ }^{\dagger}$ María San Anselmo, ${ }^{\dagger}$ \\ Enrique Gutiérrez-Puebla, ${ }^{\dagger}$ José L. Serrano, ${ }^{\ddagger 0}$ and Berta Gómez-Lor* ${ }^{*} \dagger(0$ \\ ${ }^{\dagger}$ Material Science Factory, Instituto de Ciencia de Materiales de Madrid, Cantoblanco, 20849 Madrid, Spain \\ ${ }^{\ddagger}$ Dpto. Química Orgánica, Instituto de Nanociencia de Aragón, Universidad de Zaragoza, 50009, Zaragoza, Spain
}

\section{Supporting Information}

\begin{abstract}
We report here on a series of redox active benzothiadiazole-based luminophores functionalized on one edge with a phenyl-nonyl substituent, which confers these molecules a rodlike shape and a tendency to self-assemble into layered superstructures. On the other edge, the molecules are endowed with different p-substituted phenyl rings, which allows the modulation of their redox and optical properties on the basis of the electronic nature of the terminal substituents. We have found that just one lateral alkyl chain is sufficient to induce mesomorphism in these molecules, which present nematic or smectic mesophases upon thermal treatment. Single-crystal analysis allows us to get an insight into the

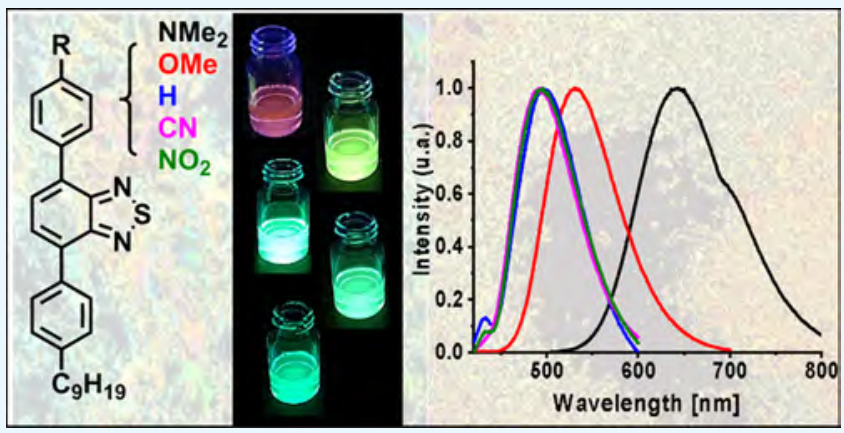
nature of the forces responsible for different supramolecular assemblies in these derivatives, and point to a strong contribution of the terminal groups in the different arrangements observed. The interesting redox and optical properties together with their self-assembling tendencies render these new materials interesting candidates for optoelectronics.
\end{abstract}

\section{INTRODUCTION}

The area of organic electronics has evolved in only a few years from basic research to the development of devices such as organic light emitting diodes (OLEDs), which are already being massively commercialized. ${ }^{1,2}$ Organic active layers can be usually implemented in devices by different solutionprocessing techniques in contrast to the expensive lithography and vacuum techniques required for silicon-based materials offering interesting opportunities to obtain low-cost devices.

On the other hand, the high versatility of organic chemistry allows the rational development of organic materials, with a high control of their final properties. Fundamental parameters for the development of molecules for their incorporation in (opto)electronic devices, such as light emission or absorption properties, energy levels, etc., can be designed "a la carte", thanks to the deep knowledge that has been acquired in the last few years through numerous structure-properties studies. ${ }^{3}$ Unfortunately, our ability to predict/control the supramolecular arrangement of electro/photoactive molecules is still very limited, although the electronic properties of organic materials depend not only on those of the building units but also on how the molecules are organized in the bulk.

Thus, in the search of device-oriented molecular systems, self-assembling materials, ${ }^{4}$ able to self-organize, through the cooperation of different intramolecular forces, represent interesting candidates in the area. In this context, liquid crystalline ordering has emerged as an attractive concept in the development of materials for (opto)electronic applications.
The dynamic character of the mesophases confers to them interesting self-healing properties and facilitates their processing as highly ordered thin films from solution or melt. The design principles to induce liquid-crystalline phases are well established and usually require a molecular disk-shaped (discotic liquid crystals) or rod-shaped (calamitic liquid crystals) $\pi$-conjugated core, functionalized with alkyl chains on their periphery to induce microphase segregation upon thermal heating. ${ }^{7}$ Discotic liquid crystals, with their highly anisotropic columnar organization, have been long identified as one-dimensional semiconductors, ${ }^{8-11}$ exhibiting, in some cases, remarkable hole ${ }^{12,13}$ and electron ${ }^{14,15}$ mobility values. However, the anisotropic character of charge transport in these systems and the difficult alignment of the columns on substrates with an edge-on configuration have hampered their incorporation in devices ${ }^{16-18}$ Although less explored in this area, calamitic liquid crystals that are much more fluid and easy to align have emerged as interesting alternatives. ${ }^{19-22}$ Particularly, the smectic mesophases found in different monoalkyl rod-shaped molecules have been demonstrated to be promising vehicles to obtain homogeneous films with reduced grain boundaries and a favorable layered arrangement for charge transport. ${ }^{20,22}$

Received: July 18, 2018

Accepted: September 11, 2018

Published: September 25, 2018 
Scheme 1. Synthesis of Compounds 2-7

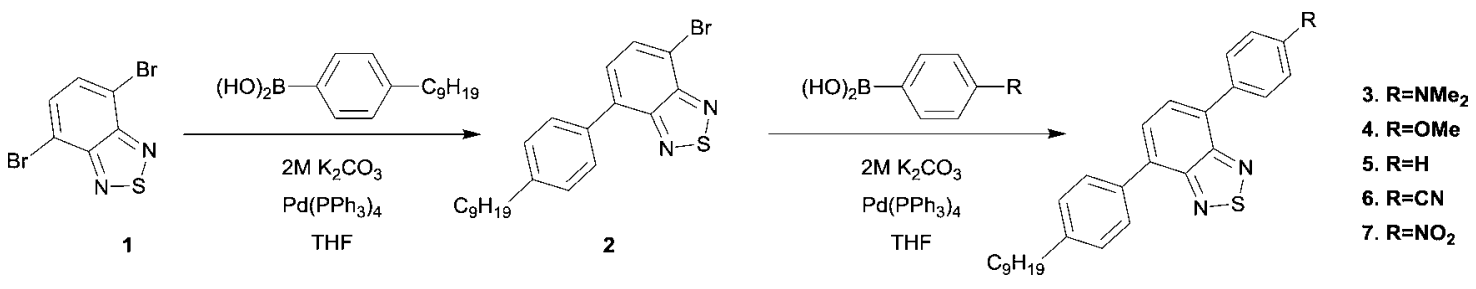

Table 1. Thermal Stability and Mesogenic Properties of 3-7

$\begin{array}{cc}\text { compounds } & T_{2 \%}\left({ }^{\circ} \mathrm{C}\right)^{a} \\ 3 & 220 \\ 4 & 284 \\ 5 & 272 \\ 6 & 302 \\ 7 & 274\end{array}$

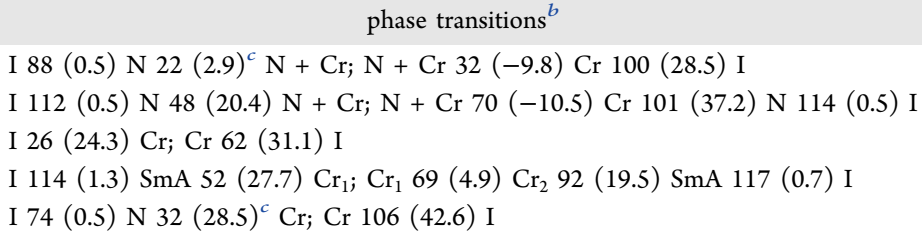

${ }^{a}$ Temperature at which $2 \%$ mass lost is detected in the thermogravimetric curve. ${ }^{b} \mathrm{DSC}$ data of the first cooling process and the second heating process at a rate of $10^{\circ} \mathrm{C} \mathrm{m^{-1 }}$. Temperatures are read at the maximum of the corresponding peaks, and enthalpies $\left(\mathrm{kJ} \mathrm{mol}{ }^{-1}\right)$ are in brackets. Cr: crystal, N: nematic mesophase, SmA: smectic A mesophase, I: isotropic liquid. ${ }^{c}$ Monotropic liquid crystals, data obtained in the second cooling process.
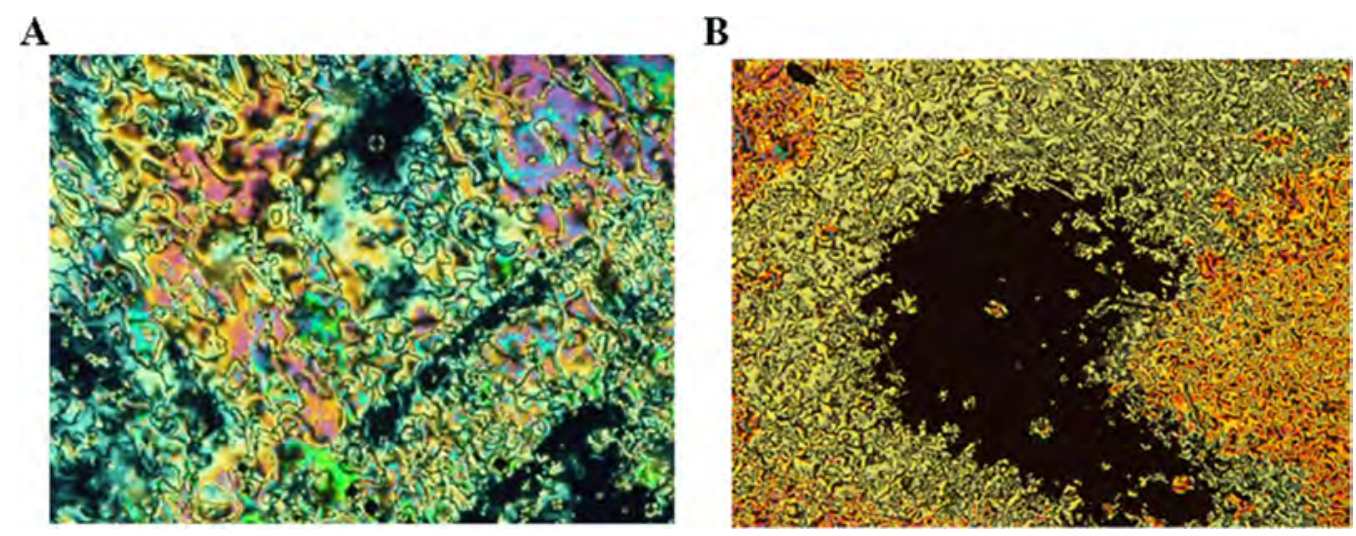

Figure 1. Micrograph of the textures observed by POM for (A) 4 at $90{ }^{\circ} \mathrm{C}$ (cooling, 20x) and (B) 6 at $90{ }^{\circ} \mathrm{C}$ (cooling, 20x).

In the last few years, the benzothiadiazole (BTD) core has emerged as a promising molecular design motif in the development of device-oriented small molecule and polymeric materials. This electron-deficient moiety presents interesting $n$ type semiconducting properties and high fluorescence quantum efficiencies and has a strong propensity to adopt quinoid conformations, thus facilitating charge transfer (CT) between attached substituents and enabling the tuning of its electronic properties. Because of these attractive properties, this molecule has been extensively incorporated as an active layer in electronic devices. ${ }^{23-26}$ By symmetrical functionalization with two aryl groups endowed with flexible chains, several BTD-based nematic and smectic liquid crystals ${ }^{27}$ have been synthesized and incorporated as an active layer in organic field effect transistors (OFETs) ${ }^{24}$ or as highly dichroic fluorescent dyes for liquid crystal displays. ${ }^{28}$ However, to our knowledge, asymmetric monoalkyl liquid crystalline BTD derivatives have not yet been reported.

In this manuscript, we describe the synthesis and the electronic and self-assembling properties of a series of asymmetrically functionalized rod-shaped electroactive benzothiadiazole derivatives, presenting interesting redox and lightemitting properties. These molecules are endowed on one edge with a phenyl-nonyl substituent and on the other edge with different p-substituted phenyl rings. Interestingly, we have found that just one lateral alkyl chain is enough to induce mesomorphism in these molecules that present nematic or smectic mesophases upon thermal treatment, which allows us to use the other terminal substituent to modulate their electronic properties. Thus, by systematic variation of the electronic nature of these substituents, we could fine-tune the redox and optical properties of these derivatives. The attached substituents also play a key role in how these molecules selfassemble in crystalline or liquid crystalline phases by participating in different intermolecular interactions, as could be unequivocally determined through single-crystal analysis.

\section{RESULTS AND DISCUSSION}

The synthesis of compounds 3-7 was performed in two steps of palladium-catalyzed Suzuki cross-coupling reactions (Scheme 1). Initially 4,7-dibromo-2,1,3-benzothiadiazole 1 was reacted with 1 equiv of 4-nonylphenylboronic acid. Under thermal heating conditions, compound $\mathbf{2}$ is obtained, along with some byproduct of double coupling and unreacted dibrominated benzothiadiazole. Monocoupling can be favored by using microwave heating conditions, which provides compound 2 in good yield in just $3 \mathrm{~h}$. Starting from 2, compounds 3-7 were synthesized straightforwardly in the 
second step by Suzuki cross-coupling with the corresponding p-substituted phenyl boronic acid under microwave heating. All new compounds were purified by silica gel column chromatography, using a mixture of hexane $/ \mathrm{CH}_{2} \mathrm{Cl}_{2}(3: 1)$ as eluent and characterized by ${ }^{1} \mathrm{H}$ NMR, ${ }^{13} \mathrm{C} N M R$, and mass spectrometry.

Study of the Self-Assembling Properties. Liquid Crystalline Properties. With the aim of investigating the propensity of these compounds to organize in smectic/nematic mesophases, we studied their thermal properties. Please note that although several rod-shaped BTD-based nematic and smectic liquid crystals have been reported, to our knowledge, all of them exhibit a $C_{2}$ symmetry. ${ }^{24,27,28}$

The thermal transitions and mesomorphic properties were studied by polarizing optical microscopy (POM), differential scanning calorimetry (DSC), and X-ray diffraction (XRD). With the exception of $\mathbf{5}$, all of these derivatives showed mesomorphic properties (see Table 1 and the Supporting Information).

Derivatives 4 and 6 displayed enantiotropic liquid crystalline mesophases, whereas 3 and 7 exhibited monotropic liquid crystalline behavior. Schlieren textures with homeotropic domains were obtained by POM for all four compounds, indicating that the mesophases have an orthogonal character (Figure 1).

To determine the nature of the mesophases and the structural parameters, we performed the XRD studies. The diffractograms recorded for 3,4 , and 7 only contains broad diffuse maxima, suggesting the absence of a long-range positional order in the liquid crystal phase. These types of patterns are typical of nematic mesophases, which have only orientational order.

In contrast, the diffractogram of compound $\mathbf{6}$ is in agreement with a smectic phase, which has been assigned as a smectic A organization, given the orthogonal character of the mesophases deduced from the presence of homeotropic domains in the textures observed by POM. Its X-ray diffraction pattern shows a sharp, strong maximum in the small-angle region (assigned to the first-order reflection of the smectic layer) and a diffuse halo (related to the conformational disorder of the liquid-like chain in the high-angle region). A layer spacing of $39.4 \AA$ was deduced by applying the Bragg's law to the small-angle maximum. This spacing is significantly larger than the molecular length in its most extended conformation $(25.2 \AA)$, which suggests that the mesophase adopts a bilayer structure.

This bilayer arrangement is reminiscent of that observed in cyanobiphenyl liquid crystals, ${ }^{29,30}$ the first liquid crystals with technological applications, and points to an important contribution of the nitrile groups in the smectic behavior of this compound via dipole-dipole interactions. Please note that the use of promesogenic cyanobiphenyl core continues to play a fundamental role in the liquid crystals arena. ${ }^{31-35}$

Crystal Structure. To shed light on the influence of the substituents on the different arrangements observed, we attempted to grow single crystals of different compounds. Single crystals of sufficient quality for structure determination were obtained for 4,6 , and 7 by slow evaporation of $1: 1$ $\mathrm{CH}_{2} \mathrm{Cl}_{2} / \mathrm{CH}_{3} \mathrm{CN}$ solutions at room temperature. We found that the terminal substituents also significantly affect the selfassembling trends of these molecules, as they are involved in intermolecular interactions with the BTD core, or in the case of the cyano groups by establishing dipolar interactions among the terminal nitriles.

Compound 4 crystallizes in the triclinic space group $P \overline{1}$, with two independent molecules in the asymmetric unit. The main difference between the two independent units is derived from different torsion angles between the BTD unit and the phenyl linkers, which, in each molecule, are rotated in opposite directions (by 39.44 and $31.88^{\circ}$ in one of the molecules and by 33.73 and $27.42^{\circ}$ in the other).

The compound crystallizes to form dimers, which are stabilized by $\mathrm{O} \cdots \mathrm{S}(2.964 \AA)$ and $\mathrm{CH} \cdots \mathrm{N}(2.877 \AA)$ interactions (Figure 2a). These dimers form layers driven by

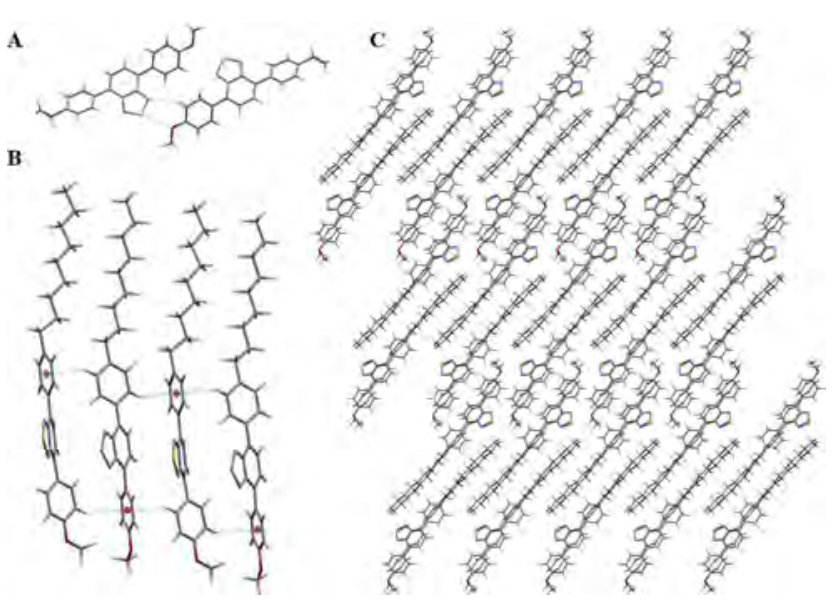

Figure 2. Depiction of the intermolecular interactions of 4 (A) between dimers and (B) between molecules of the same layer. (C) Crystal packing view along (a).

$\mathrm{C}-\mathrm{H} \cdots \pi$ interactions involving the neighboring phenyl rings (Figure $2 \mathrm{~b}$ ), whereas the BTD rings are situated in a paralleldisplaced arrangement. The long alkyl chains are strongly interdigitated (Figure 2c).

Compound 6 crystallizes in the monoclinic space group C2/ $c$, with two independent molecules in the asymmetric unit. Again the main difference between two independent units is derived from different torsion angles between the BTD unit and the phenyl linkers, which, in this case, are rotated in the same directions (by 48.36 and $44.88^{\circ}$ in one of the molecules and by 46.32 and $45.73^{\circ}$ in the other).

The analysis of the crystal packing shows that 6 is organized in a bilayered structure, as previously observed in the mesophases (Figure 3). An analysis of the close contacts in the structure evidences the antiparallel coupling of the cyano end groups, demonstrating the leading role of the nitrile groups in the attained bimolecular arrangement, via dipolar interactions. No interdigitation of the alkyl chains can be detected in this case.

Compound 7 crystallizes in the monoclinic space group $P 2_{1} /$ $c$ and has one independent molecule in the asymmetric unit. Both phenyl rings are rotated in the same directions by 31.69 and $37.90^{\circ}$ with respect to the BTD unit.

The molecules adopt an extended conformation and arrange in a highly compact superstructure, in which the molecules grow with their long axis nearly parallel to the $a$-axis of the unit cell (Figure 4). The analysis of the short contacts in the crystal packing shows a nonbonded interaction between the sulfur atom and one of the oxygen atoms of the nitro group situated at an interatomic distance of $3.0 \AA$. This indicates that again 
A

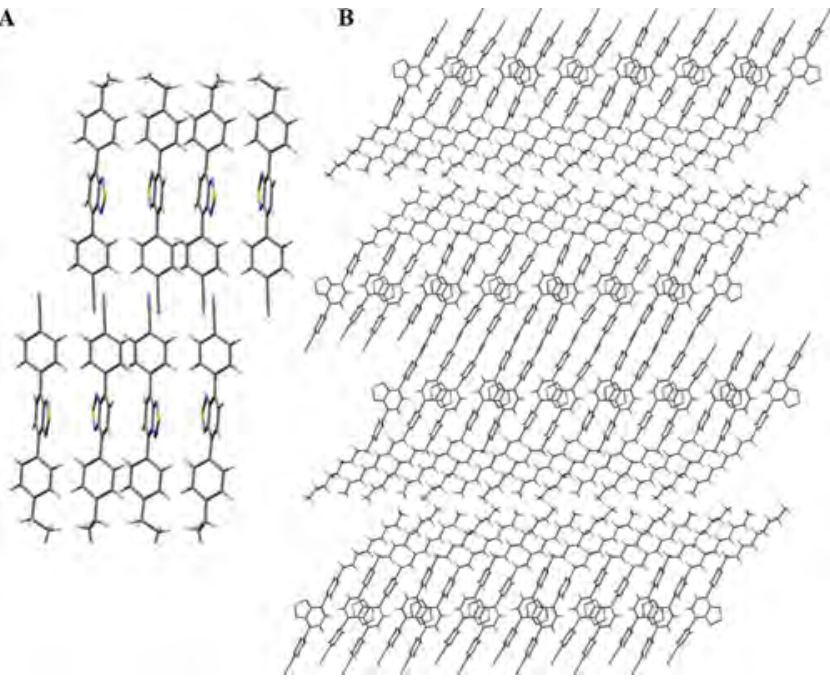

Figure 3. Depiction of the intermolecular interactions of 6 (A) between molecules of the same layer. (B) Crystal packing view along (b).

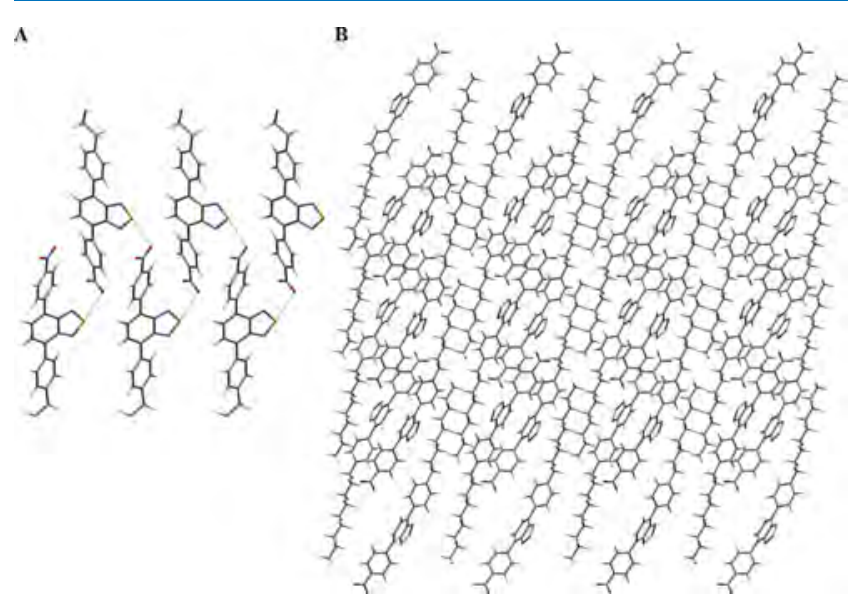

Figure 4. Depiction of the intermolecular interactions of 7 (A) between molecules of the same layer. (B) Crystal packing view along (b).

the stabilization of this structure involves the attached functional groups.

Electronic Properties. The tendency of these molecules to self-assemble into layered arrangements, as shown above, render them very attractive for the easy formation of ordered thin films to be implemented in devices. In the search for molecules that can be incorporated in the devices, it is also highly desirable to be able to fine tune their electronic properties. With this in mind, we have investigated how the electronic nature of the terminal groups influence the optical and redox properties of these molecules by means of optical
(UV-vis absorption and fluorescence) spectroscopy and cyclic voltammetry $(\mathrm{CV})$.

The absorption properties of the BTD derivatives 3-7 were recorded in a $10^{-5} \mathrm{M}$ dichloromethane solution by UV-vis spectroscopy at room temperature. All of the derivatives show two absorption bands: one at high energies associated with the $\pi \rightarrow \pi^{*}$ transitions of the molecule and other at lower energies assigned to charge transfer (CT) transition involving the end groups. In compounds 3 and $\mathbf{4}$, which are substituted with electron-donor groups, the CT band is red-shifted. This behavior is more notable for 3 functionalized with the strongest dimethylamine donor (Table 2 and Figure 5a).

The electrochemical properties of the compounds 3-7 were investigated by cyclic voltammetry (CV). All of the compounds can be easily reduced to stable radical anions, thus reflecting the strong acceptor character of the BTD core. The reduction potential of the derivatives substituted with electron donors is nearly identical; however, the reduction potentials move to less negative values as the electron-acceptor character of the substituents is increased and therefore the electron density in the $\pi$ system is lowered.

Interestingly, derivatives $3 \mathbf{- 5}$ present an amphoteric redox character, as they can be also easily oxidized in the accessible solvent window and the oxidation potentials shifts anodically with increase in the acceptor character of the substituent. Compound 3 presents a second oxidation wave because of the oxidation of the $\mathrm{NMe}_{2}$ group (Table 2 and Figure $5 \mathrm{~b}$ ).

The energy of the HOMO-LUMO levels of compounds 3-5 was estimated from their first oxidation and the reduction potentials respectively, by referring the potentials to the ferrocene/ferrocenium redox couple and considering a value of $-4.8 \mathrm{eV}$ for ferrocene with respect to zero vacuum level. In compounds 6 and 7, which show only a reduction process, the HOMO level was calculated by subtracting the value of the optical gap from that of the LUMO level, estimated electrochemically.

The position of the HOMO and LUMO levels calculated for 3 and $\mathbf{4}$ are adequate for the easy injection of electrons and holes from common electrodes of much relevance for potential electronic applications. Conversely, those of 5-7 are more appropriate for the easy injection of electrons (see Table 2).

All of these compounds emit intensely in a solution and their emission wavelengths are also strongly influenced by the electronic nature of the substituents. In $10^{-5} \mathrm{M}$ dichloromethane solutions, compounds 5-7 emit cyan fluorescence, with maxima being barely affected by the electron-withdrawing character of the substituents. Conversely, the emission of compounds 3 and $\mathbf{4}$ is significantly red-shifted as a result of their increased intramolecular charge transfer.

Compound 3 presents an orange-red fluorescence at 644 $\mathrm{nm}$, whereas 4 exhibits a maximum at $532 \mathrm{~nm}$ with the emission of a shiny yellow color (Table 2 and Figure 5a). High

Table 2. UV-Vis and Fluorescence Spectroscopic and Redox Properties of 3-7 in $\mathrm{CH}_{2} \mathrm{Cl}_{2}$ and Estimated Highest Occupied Molecular Orbital (HOMO) and Lowest Unoccupied Molecular Orbital (LUMO) Energies

$\begin{array}{ccc}\text { compounds } & \lambda_{\max }^{\mathrm{abs}}(\mathrm{nm}) & \lambda_{\max }^{\mathrm{em}}(\mathrm{nm}) \\ \mathbf{3} & 446 & 644 \\ 4 & 399 & 532 \\ \mathbf{5} & 385 & 496 \\ 6 & 384 & 494 \\ 7 & 388 & 496\end{array}$

$E_{\mathrm{gap}}^{\mathrm{opt}}(\mathrm{eV})$
2.33
2.70
2.86
2.83
2.83

$E_{1 / 2}^{\text {red }}$
-1.49
-1.46
-1.44
-1.32
-1.03

$E_{1 / 2}^{\mathrm{ox}}$
0.80
1.41
1.64

$\mathrm{HOMO}(\mathrm{eV})$
5.17
5.74
6.01
5.88
6.18

LUMO $(\mathrm{eV})$
2.87
2.88
2.94
3.05
3.35


A

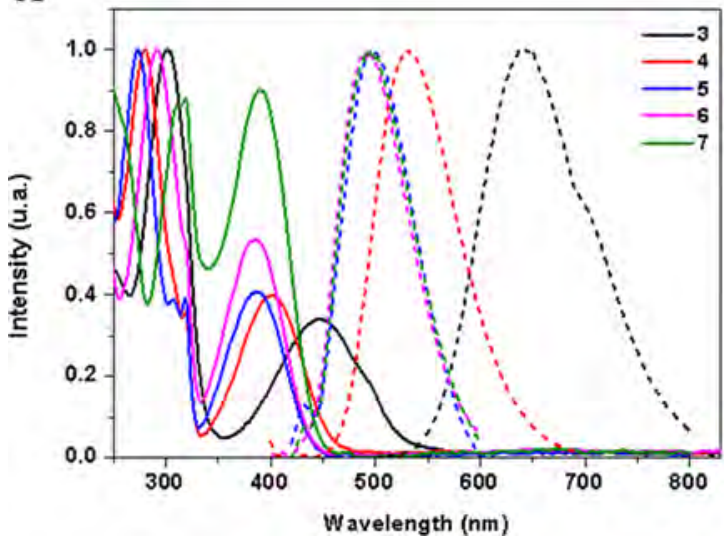

B

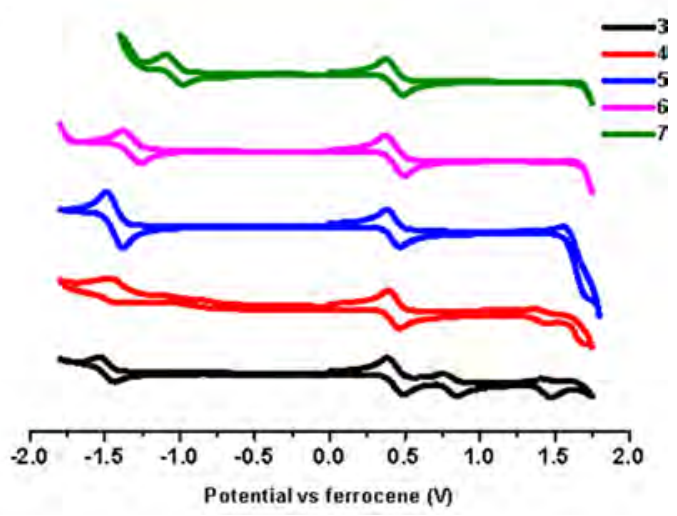

Figure 5. (A) Normalized UV-vis (lines) and fluorescence (dots) spectra of compounds 3-7 in $\mathrm{CH}_{2} \mathrm{Cl}_{2}, c=5 \times 10^{-6} \mathrm{M}$ solutions and (B) cyclic voltammograms of compounds $3-7$ at $c=1 \times 10^{-3} \mathrm{M}$ recorded at a scan rate $100 \mathrm{mV} \mathrm{s}{ }^{-1}$ in $\mathrm{CH}_{2} \mathrm{Cl}_{2} / 0.1 \mathrm{M} \mathrm{TBAPF}$ measured versus $\mathrm{Ag} / \mathrm{AgCl}$ and using ferrocene as an internal reference.

Stokes shifts are observed in all of the cases, which again show a strong dependence of the nature of the terminal substituents; 5-7 present Stokes shifts around $110 \mathrm{~nm}$ and 3 and 4 show Stokes shifts of 198 and $133 \mathrm{~nm}$, respectively.

We have investigated the light-emitting properties of these compounds in different environments. The fluorescence spectra of compounds 3-7 show a strong solvent dependence. The emission bands shift bathochromically as the solvent polarity is increased. This behavior is more significant in compound 3, with a higher charge-transfer character, whose emission maximum shows a remarkable shift of more than 100 $\mathrm{nm}$ from cyclohexane $(541 \mathrm{~nm})$ to $\mathrm{CH}_{2} \mathrm{Cl}_{2}(645 \mathrm{~nm})$ and fluorescence is completely quenched in $\mathrm{MeOH}$. The strong influence of the polarity of the solvent in the emission properties of 3 is probably related to the formation of twisted intramolecular charge-transfer states in this compound. ${ }^{36}$ The environmental sensitivity of the light-emitting properties of this compound represents a promising property toward its application in sensing/bioimaging.

Interestingly, all of these compounds emit intensely also in solid state and mesophase. Please note that strong intermolecular interaction and close packing usually lead to quenching of emission. In the condensed states, the maximum emission wavelengths are slightly blue-shifted when compared to the fluorescence in $\mathrm{CH}_{2} \mathrm{Cl}_{2}$ solution (Table 3). The

Table 3. Maximum Emission Wavelength in Different Solvent Systems

\begin{tabular}{ccccccc} 
compounds & cyclohexane & $\mathrm{CH}_{2} \mathrm{Cl}_{2}$ & THF & $\mathrm{MeOH}$ & crystal & mesophase \\
$\mathbf{3}$ & 541 & 645 & 635 & & 580 & 612 \\
$\mathbf{4}$ & 494 & 532 & 523 & 554 & 509 & 528 \\
$\mathbf{5}$ & 475 & 497 & 492 & 512 & 488 & \\
$\mathbf{6}$ & 471 & 494 & 487 & 499 & 484 & 503 \\
7 & 470 & 496 & 488 & 501 & 487 & 506 \\
\hline
\end{tabular}

observed hypsochromism is probably associated with higher dihedral angles between the phenyl rings and the benzothiadiazole cores in the more constrained environments of the crystalline and liquid crystalline phases, which would reduce the extent of $\pi$-delocalization in these rod-shaped compounds.

\section{CONCLUSIONS}

In conclusion, a new series of redox active monoalkyl liquid crystalline BTD fluorophores functionalized on one edge with a phenyl-nonyl substituent and on the other edge with different p-substituted phenyl rings have been synthesized and characterized with the aim of finding molecules of potential interest for electronic applications.

We have found that attaching only one terminal alkyl chain to the 4,7-diphenyl BTD core is enough to induce mesomorphism in these molecules and to prompt their selfassembly into layered supramolecular arrangements, as could be determined by the single-crystal analysis. The other terminal groups allow fine-tuning of the electronic properties of these molecules (by influencing the intramolecular charge transfer in the system) and the modulation of their mesomorphic behavior and crystal packing by participating in different intermolecular interactions.

The easy reversible oxidation/reductions of these BTD derivatives and adequate HOMO-LUMO levels for the easy injection of charge carriers, together with their efficient lightemitting properties and tendency to self-assemble to form layered arrangements (highly favorable for charge/exciton migration transport), make these derivatives promising candidates for incorporation in devices such as OLEDs and OFETs. Compound $\mathbf{6}$ especially has a remarkable bilayer arrangement, which together with its favorable amphoteric redox properties renders it a promising candidate for ambipolar OFETs. Work along these lines is in progress.

\section{EXPERIMENTAL SECTION}

Materials Synthesis. Synthesis of 4-Bromo-7-(4nonylphenyl)benzo[c][1,2,5]thiadiazole (2). A solution of 4,7-dibromo[c][1,2,5] thiadiazole $(250 \mathrm{mg}, 0.85 \mathrm{mmol})$, Pd$\left(\mathrm{PPh}_{3}\right)_{4}(59.0 \mathrm{mg}, 0.051 \mathrm{mmol})$, and 4-nonylphenyl boronic acid (221 mg, $0.89 \mathrm{mmol}$ ) in a mixture of $2 \mathrm{M}$ aqueous $\mathrm{K}_{2} \mathrm{CO}_{3}$ $(0.5 \mathrm{~mL})$ and dry tetrahydrofuran (THF, $5 \mathrm{~mL})$ was degassed and irradiated with an Anton Paar microwave irradiator $(\mathrm{CEM})$ at $150{ }^{\circ} \mathrm{C}(80 \mathrm{~W})$ for $180 \mathrm{~min}$. After cooling to room temperature, the reaction mixture was concentrated. The solid was diluted with $\mathrm{CH}_{2} \mathrm{Cl}_{2}$, washed with water, and dried over $\mathrm{MgSO}_{4}$ anhydrous. The solvent was evaporated and the residue was purified by column chromatography with $\mathrm{CH}_{2} \mathrm{Cl}_{2}$ / hexane (1:3) to give a pale yellow solid (2) (333.7 $\mathrm{mg}, 94 \%)$. 
${ }^{1} \mathrm{H}$ NMR $\left(300 \mathrm{MHz}, \mathrm{CDCl}_{3}\right) \delta 7.82(\mathrm{~d}, J=7.5 \mathrm{~Hz}, 1 \mathrm{H})$, $7.78(\mathrm{~d}, J=8.1 \mathrm{~Hz}, 2 \mathrm{H}), 7.48(\mathrm{~d}, J=7.5 \mathrm{~Hz}, 1 \mathrm{H}), 7.32(\mathrm{~d}, J=$ $8.0 \mathrm{~Hz}, 2 \mathrm{H}), 2.88-2.47(\mathrm{~m}, 2 \mathrm{H}), 1.76-1.63(\mathrm{~m}, 2 \mathrm{H}), 1.43-$ $1.23(\mathrm{~m}, 12 \mathrm{H}), 1.00-0.84(\mathrm{~m}, 3 \mathrm{H}) ;{ }^{13} \mathrm{C}$ NMR $(50 \mathrm{MHz}$, $\left.\mathrm{CDCl}_{3}\right) \delta 153.9,153.3,143.8,134.1,133.9,132.3,129.0$, 128.8, 127.9, 112.7, 35.8, 31.9, 31.4, 29.53, 29.3, 22.7, 14.1; $\mathrm{UV}$-vis $\left(\mathrm{CH}_{2} \mathrm{Cl}_{2}, 25^{\circ} \mathrm{C}\right): \lambda_{\max }(\mathrm{nm}) 244,307,377$; MS (FAB, $m / z)$ : $417.41\left(\mathrm{M}^{+}\right)$. HRMS (FAB) calcd for $\mathrm{C}_{21} \mathrm{H}_{25} \mathrm{~N}_{2} \mathrm{SBr}$ : 416.0922, found: 416.0923 .

Synthesis of N,N-Dimethyl-4-(7-(4-nonylphenyl)benzo[c][1,2,5]thiadiazol-4-yl)aniline (3). A solution of 4,7-dibromo$[c][1,2,5]$ thiadiazole $(150 \mathrm{mg}, 0.36 \mathrm{mmol}), \mathrm{Pd}\left(\mathrm{PPh}_{3}\right)_{4}(35.4$ $\mathrm{mg}, 0.031 \mathrm{mmol}$ ), and (4-(dimethylamino)phenyl)boronic acid $(59.4 \mathrm{mg}, 0.36 \mathrm{mmol}$ ) in a mixture of $2 \mathrm{M}$ aqueous $\mathrm{K}_{2} \mathrm{CO}_{3}(0.3 \mathrm{~mL})$ and dry THF $(2 \mathrm{~mL})$ was degassed and irradiated with an Anton Paar microwave irradiator (CEM) at $150{ }^{\circ} \mathrm{C}(80 \mathrm{~W})$ for $180 \mathrm{~min}$. After cooling to room temperature, the reaction mixture was diluted with $\mathrm{CH}_{2} \mathrm{Cl}_{2}$, washed with water, and dried over $\mathrm{MgSO}_{4}$ anhydrous. Then, the solvent was evaporated and the residue was purified by column chromatography with hexane/ $\mathrm{CH}_{2} \mathrm{Cl}_{2}(1: 1)$ to give a red solid (3) (45 $\mathrm{mg}, 28 \%$ ).

${ }^{1} \mathrm{H}$ NMR $\left(200 \mathrm{MHz}^{\mathrm{CDCl}}{ }_{3}\right) \delta 7.92(\mathrm{~d}, J=8.8 \mathrm{~Hz}, 2 \mathrm{H})$, $7.87(\mathrm{~d}, J=8.1 \mathrm{~Hz}, 2 \mathrm{H}), 7.72(\mathrm{~d}, J=1.2 \mathrm{~Hz}, 2 \mathrm{H}), 7.35$ (d, $J=$ $8.0 \mathrm{~Hz}, 2 \mathrm{H}), 6.90(\mathrm{~d}, J=8.9 \mathrm{~Hz}, 2 \mathrm{H}), 3.05(\mathrm{~s}, 6 \mathrm{H}), 2.73-2.63$ $(\mathrm{m}, 2 \mathrm{H}), 1.77-1.59(\mathrm{~m}, 2 \mathrm{H}), 1.39-1.23(\mathrm{~m}, 12 \mathrm{H}), 0.88(\mathrm{t}, J=$ $6.3 \mathrm{~Hz}, 3 \mathrm{H}) ;{ }^{13} \mathrm{C} \mathrm{NMR}\left(75 \mathrm{MHz}, \mathrm{CDCl}_{3}\right) \delta 162.3,154.5$, 143.2 , 135.1, 133.1, 132.2, 130.55, 130.3, 129.1, 128.8, 128.2, 126.7, 122.3, 113.2, 41.1, 36.0, 32.0, 31.6, 31.4, 29.7, 29.6, 29.6, 29.5, 22.8, 14.3; UV ( $\left.\mathrm{CH}_{2} \mathrm{Cl}_{2}, 25^{\circ} \mathrm{C}\right): \lambda_{\max }(\mathrm{nm}) 300,400$; MS $(\mathrm{FAB}, m / z)$ : $457.1\left(\mathrm{M}^{+}\right)$. HRMS (ESI) calcd for $\mathrm{C}_{29} \mathrm{H}_{35} \mathrm{~N}_{3} \mathrm{~S}$ : 457.25675, found: 457.25517 .

Synthesis of 4-(4-Methoxyphenyl)-7-(4-nonylphenyl)benzo[c][1,2,5]thiadiazole (4). A solution of 4,7-dibromo[c]$[1,2,5]$ thiadiazole $(150 \mathrm{mg}, 0.36 \mathrm{mmol}), \mathrm{Pd}\left(\mathrm{PPh}_{3}\right)_{4}(58.1 \mathrm{mg}$, $0.050 \mathrm{mmol}$ ), and 4-methoxyphenyl boronic acid $(54.7 \mathrm{mg}$, $0.36 \mathrm{mmol})$ in a mixture of $2 \mathrm{M}$ aqueous $\mathrm{K}_{2} \mathrm{CO}_{3}(0.3 \mathrm{~mL})$ and dry THF $(2 \mathrm{~mL})$ was degassed and irradiated with an Anton Paar microwave irradiator (CEM) at $150{ }^{\circ} \mathrm{C}(80 \mathrm{~W})$ for 180 $\mathrm{min}$. After cooling to room temperature, the reaction mixture was diluted with $\mathrm{CH}_{2} \mathrm{Cl}_{2}$, washed with water, and dried over $\mathrm{MgSO}_{4}$ anhydrous. Then, the solvent was evaporated and the residue was purified by column chromatography with hexane/ $\mathrm{CH}_{2} \mathrm{Cl}_{2}$ (3:1) to give a fluorescent greenish-yellow solid (4) (95.2 mg, 68\%).

${ }^{1} \mathrm{H}$ NMR $\left(200 \mathrm{MHz}, \mathrm{CDCl}_{3}\right) \delta 7.93(\mathrm{~d}, J=9.1 \mathrm{~Hz}, 2 \mathrm{H})$, $7.87(\mathrm{~d}, J=8.1 \mathrm{~Hz}, 2 \mathrm{H}), 7.74(\mathrm{~s}, 2 \mathrm{H}), 7.36(\mathrm{~d}, J=8.1 \mathrm{~Hz}$, $2 \mathrm{H}), 7.09(\mathrm{~d}, J=9.1 \mathrm{~Hz}, 2 \mathrm{H}), 3.90(\mathrm{~s}, 3 \mathrm{H}), 2.70(\mathrm{t}, J=7.5 \mathrm{~Hz}$, $2 \mathrm{H}), 1.77-1.60(\mathrm{~m}, 2 \mathrm{H}), 1.31(\mathrm{~m}, 12 \mathrm{H}), 0.98-0.80(\mathrm{~m}, 3 \mathrm{H})$; ${ }^{13} \mathrm{C}$ NMR (50 $\left.\mathrm{MHz}, \mathrm{CDCl}_{3}\right) \delta 160.0,154.4,143.4,135.0$, $132.9,130.6,130.2,129.2,128.9,128.0,127.5,114.3,55.6$, 36.0, 32.1, 31.6, 29.7, 29.6, 29.5, 22.8, 14.3; UV $\left(\mathrm{CH}_{2} \mathrm{Cl}_{2}, 25\right.$ $\left.{ }^{\circ} \mathrm{C}\right) \lambda_{\max }(\mathrm{nm}) 246,280,399 ; \mathrm{MS}$ (MALDI, $\left.m / z\right): 444.3\left(\mathrm{M}^{+}\right)$, HRMS (ESI) calcd for $\mathrm{C}_{28} \mathrm{H}_{32} \mathrm{~N}_{2} \mathrm{OS}$ : 444.22262, found: 444.22353.

Synthesis of 4-(4-Nonylphenyl)-7-phenylbenzo[c][1,2,5]thiadiazole (5). A solution of 4,7-dibromo[c][1,2,5] thiadiazole $(150 \mathrm{mg}, 0.36 \mathrm{mmol}), \mathrm{Pd}\left(\mathrm{PPh}_{3}\right)_{4}(58.9 \mathrm{mg}, 0.050 \mathrm{mmol})$ and phenylboronic acid $(43.9 \mathrm{mg}, 0.36 \mathrm{mmol})$ in a mixture of $2 \mathrm{M}$ aqueous $\mathrm{K}_{2} \mathrm{CO}_{3}(0.3 \mathrm{~mL})$ and dry THF $(2 \mathrm{~mL})$ was degassed and irradiated with an Anton Paar microwave irradiator $(\mathrm{CEM})$ at $150{ }^{\circ} \mathrm{C}(80 \mathrm{~W})$ for $180 \mathrm{~min}$. After cooling to room temperature, the reaction mixture was diluted with $\mathrm{CH}_{2} \mathrm{Cl}_{2}$, washed with water, and dried over $\mathrm{MgSO}_{4}$ anhydrous. Then, the solvent was evaporated and the residue was purified by column chromatography with hexane $/ \mathrm{CH}_{2} \mathrm{Cl}_{2}(4: 1)$ to give a pale yellow solid (5) $(80.5 \mathrm{mg}, 54 \%)$.

${ }^{1} \mathrm{H} \mathrm{NMR}\left(300 \mathrm{MHz}, \mathrm{CDCl}_{3}\right) \delta 7.97(\mathrm{~d}, J=7.0 \mathrm{~Hz}, 2 \mathrm{H})$, $7.89(\mathrm{~d}, J=8.3 \mathrm{~Hz}, 2 \mathrm{H}), 7.78(\mathrm{~s}, 2 \mathrm{H}), 7.55(\mathrm{t}, J=7.4 \mathrm{~Hz}, 2 \mathrm{H})$, $7.46(\mathrm{t}, J=7.3 \mathrm{~Hz}, 1 \mathrm{H}), 7.37(\mathrm{~d}, J=8.4 \mathrm{~Hz}, 2 \mathrm{H}), 2.76-2.62$ $(\mathrm{m}, 2 \mathrm{H}), 1.83-1.59(\mathrm{~m}, 2 \mathrm{H}), 1.44-1.17(\mathrm{~m}, 12 \mathrm{H}), 0.94-0.80$ $(\mathrm{m}, 3 \mathrm{H}) ;{ }^{13} \mathrm{C} \mathrm{NMR}\left(75 \mathrm{MHz}, \mathrm{CDCl}_{3}\right) \delta 154.3,154.2,143.5$, $137.6,134.8,133.5,133.1,129.3,129.2,128.8,128.7,128.4$, 128.3, 127.9, 36.0, 32.0, 31.9, 31.6, 29.7, 29.6, 29.5, 22.8, 14.3; $\mathrm{UV}\left(\mathrm{CH}_{2} \mathrm{Cl}_{2}, 25^{\circ} \mathrm{C}\right) \lambda_{\max }(\mathrm{nm}) 273,318,385$. MS (FAB, $m /$ $z): 414.2\left(\mathrm{M}^{+}\right)$. HRMS (ESI) calcd for $\mathrm{C}_{27} \mathrm{H}_{30} \mathrm{~N}_{2} \mathrm{~S}: 414.21377$, found: 414.21297 .

Synthesis of 4-(7-(4-Nonylphenyl)benzo[c][1,2,5]thiadiazol-4-yl)benzonitrile (6). A solution of 4,7-dibromo$[c][1,2,5]$ thiadiazole $(150 \mathrm{mg}, 0.36 \mathrm{mmol}), \mathrm{Pd}\left(\mathrm{PPh}_{3}\right)_{4}(58.8$ $\mathrm{mg}, 0.050 \mathrm{mmol})$, 4-cyanophenylboronic acid $(52.8 \mathrm{mg}, 0.36$ $\mathrm{mmol})$ in a mixture of $2 \mathrm{M}$ aqueous $\mathrm{K}_{2} \mathrm{CO}_{3}(0.3 \mathrm{~mL})$ and dry THF $(2.0 \mathrm{~mL})$ was degassed and irradiated with an Anton Paar microwave irradiator $(\mathrm{CEM})$ at $150{ }^{\circ} \mathrm{C}(80 \mathrm{~W})$ for $180 \mathrm{~min}$. After cooling to room temperature, the reaction mixture was diluted with $\mathrm{CH}_{2} \mathrm{Cl}_{2}$, washed with water, and dried over $\mathrm{MgSO}_{4}$ anhydrous. Then, the solvent was evaporated and the residue was purified by column chromatography with hexane/ $\mathrm{CH}_{2} \mathrm{Cl}_{2}$ (3:1) to give a pale light yellow solid (6) $(88.5 \mathrm{mg}$, $56 \%)$.

${ }^{1} \mathrm{H}$ NMR $\left(200 \mathrm{MHz}, \mathrm{CDCl}_{3}\right) \delta 8.12(\mathrm{~d}, J=8.1 \mathrm{~Hz}, 2 \mathrm{H})$, $7.95-7.77(\mathrm{~m}, 6 \mathrm{H}), 7.38(\mathrm{~d}, J=7.9 \mathrm{~Hz}, 2 \mathrm{H}), 2.70(\mathrm{t}, J=7.6$ $\mathrm{Hz}, 2 \mathrm{H}), 1.78-1.60(\mathrm{~m}, 2 \mathrm{H}), 1.46-1.13(\mathrm{~m}, 12 \mathrm{H}), 1.07-0.70$ $(\mathrm{m}, 3 \mathrm{H}) ;{ }^{13} \mathrm{C}$ NMR $\left(75 \mathrm{MHz}, \mathrm{CDCl}_{3}\right) \delta 154.19,153.64$, $143.95,141.91,134.97,134.34,132.40,130.66,129.85,129.24$, $128.97,128.88,127.57,118.92,111.79,35.91,32.00,31.51$, $31.01,29.79,29.67,29.65,29.51,29.44,22.78,14.23$; UV $\left(\mathrm{CH}_{2} \mathrm{Cl}_{2}, 25{ }^{\circ} \mathrm{C}\right) \lambda_{\max }(\mathrm{nm})$ 291, 384; MS (MALDI, $\left.m / z\right)$ : $439.2\left(\mathrm{M}^{+}\right)$. HRMS (ESI) calcd for $\mathrm{C}_{28} \mathrm{H}_{29} \mathrm{~N}_{3} \mathrm{~S}$ : 439.20805, found: 439.20822 .

Synthesis of 4-(4-Nitrophenyl)-7-(4-nonylphenyl)benzo[c][1,2,5]thiadiazole (7). A solution of 4,7-dibromo[c]$[1,2,5]$-thiadiazole $(150 \mathrm{mg}, 0.36 \mathrm{mmol}), \mathrm{Pd}\left(\mathrm{PPh}_{3}\right)_{4}(58.7$ $\mathrm{mg}, 0.050 \mathrm{mmol}$ ), and 4-(4-nitrophenyl)-phenylboronic acid $(60.1 \mathrm{mg}, 0.36 \mathrm{mmol})$ in a mixture of $2 \mathrm{M}$ aqueous $\mathrm{K}_{2} \mathrm{CO}_{3}$ $(0.3 \mathrm{~mL})$ and dry THF $(2 \mathrm{~mL})$ was degassed and irradiated with an Anton Paar microwave irradiator (CEM) at $150{ }^{\circ} \mathrm{C}$ $(80 \mathrm{~W})$ for $180 \mathrm{~min}$. After cooling to room temperature, the reaction mixture was diluted with $\mathrm{CH}_{2} \mathrm{Cl}_{2}$, washed with water, and dried over $\mathrm{MgSO}_{4}$ anhydrous. Then, the solvent was evaporated and the residue was purified by column chromatography with hexane/ $\mathrm{CH}_{2} \mathrm{Cl}_{2}(1: 1)$ to give a pale greenish yellow solid (7) (97.3 mg, 59\%).

${ }^{1} \mathrm{H}$ NMR $\left(300 \mathrm{MHz}, \mathrm{CDCl}_{3}\right) \delta 8.41(\mathrm{~d}, J=9.0 \mathrm{~Hz}, 2 \mathrm{H})$, $8.19(\mathrm{~d}, J=9.1 \mathrm{~Hz}, 2 \mathrm{H}), 7.90(\mathrm{~d}, J=8.2 \mathrm{~Hz}, 2 \mathrm{H}), 7.88(\mathrm{~d}, J=$ $7.3 \mathrm{~Hz}, 1 \mathrm{H}), 7.82(\mathrm{~d}, J=7.3 \mathrm{~Hz}, 1 \mathrm{H}), 7.38(\mathrm{~d}, J=8.3 \mathrm{~Hz}, 2 \mathrm{H})$, $2.71(\mathrm{~d}, J=15.4 \mathrm{~Hz}, 2 \mathrm{H}), 1.75-1.61(\mathrm{~m}, 2 \mathrm{H}), 1.50-1.21(\mathrm{~m}$, $12 \mathrm{H}), 0.89(\mathrm{~m}, 3 \mathrm{H}) .{ }^{13} \mathrm{C}$ NMR $\left(75 \mathrm{MHz}, \mathrm{CDCl}_{3}\right) \delta 154.2$, $153.7,147.5,144.1,143.8,135.2,134.3,130.2,130.0,129.3$, $129.2,128.9,127.5,123.9,35.9,32.0,31.5,29.7,29.7,29.5$, 29.5, 22.8, 14.2; UV $\left(\mathrm{CH}_{2} \mathrm{Cl}_{2}, 25^{\circ} \mathrm{C}\right) \lambda_{\max }$ (nm) 315, 520; MS (MALDI, $m / z): 460.2\left(\mathrm{M}+\mathrm{H}^{+}\right)$. HRMS (ESI) calcd for $\mathrm{C}_{27} \mathrm{H}_{29} \mathrm{~N}_{3} \mathrm{O}_{2} \mathrm{~S}$ : 459.19877 , found: 459.19805 .

X-ray Structure Determinations. Crystals of 4, 6, and 7 were mounted on a Bruker four circle kappa-diffractometer equipped with a $\mathrm{Cu}$ INCOATED microsource, operated at 30 
$\mathrm{W}$ power $(45 \mathrm{kV}, 0.60 \mathrm{~mA})$ to generate $\mathrm{Cu} \mathrm{K} \alpha$ radiation $(\lambda=$ $1.54178 \AA)$, and a Bruker VANTEC 500 area detector (microgap technology). Crystals of 4 and 7 showed welldefined faces, while crystals of $\mathbf{6}$ growed as polysynthetic twins. Diffraction data were collected exploring more than a hemisphere of the reciprocal space using a combination of $\varphi$ and $\omega$ scans to reach a resolution of $0.86 \AA$. The structures were solved by the Multan and Fourier methods. Most of the calculations were carried out with APEXII software for data collection and reduction, and OLEX2 ${ }^{37}$ for structure solution and refinements. CCDC 1834993, CCDC 1834974, and CCDC 1834997 contain the supporting crystallographic data of 4,6 , and 7 , respectively.

Crystal data for 4: $\mathrm{C}_{28} \mathrm{H}_{32} \mathrm{~N}_{2} \mathrm{OS}, M=444.61$ crystal dimensions: $0.35 \times 0.04 \times 0.02 \mathrm{~mm}^{3}$, triclinic, $P \overline{1}$ space group, unit cell dimensions: $a=9.7091(8), b=10.9090(7), c=$ 23.3387(16) $\AA, \alpha=100.685(5)^{\circ}, \beta=98.924(5)^{\circ}, \gamma=$ $95.706(5)^{\circ}, V=2378.7(3) \AA^{3}, T=250 \mathrm{~K}, Z=4, \rho_{\text {calcd }}=1.242$ $\mathrm{g} \mathrm{cm}^{-3}$. The structure was refined anisotropically $R_{1}(F)=$ 0.0685 for observed data $(I>2 \sigma(I))$, final $R$ values (all data) $R_{1}(F)=0.1663, \mathrm{wR}_{2}(F)=0.2451$ for all data.

Crystal data for 6: $\mathrm{C}_{28} \mathrm{H}_{29} \mathrm{~N}_{3} \mathrm{~S}, \quad M=439.60$ crystal dimensions: $0.50 \times 0.10 \times 0.04 \mathrm{~mm}^{3}$, monoclinic, $C 12 / \mathrm{c} 1$ space group, unit cell dimensions: $a=82.379(9), b=$ 7.9627(9), $c=14.7427(13) \AA, \alpha=90^{\circ}, \beta=93.622(7)^{\circ}, \gamma=$ $90^{\circ}, V=9651.3(17) \AA^{3}, T=200 \mathrm{~K}, Z=16, \rho_{\text {calcd }}=1.210 \mathrm{~g}$ $\mathrm{cm}^{-3}$. The structure was refined anisotropically $R_{1}(F)=0.1466$ for observed data $(I>2 \sigma(I))$, final $R$ values (all data) $R_{1}(F)=$ $0.1859, \mathrm{w}_{2}(F)=0.3417$ for all data. Two independent molecules are present in the structure showing one of them thermal noresolvable disorder. Seven soft restrictions (4 DFIX, 3 DELU) have been applied to the disordered molecule.

Crystal data for 7: $\mathrm{C}_{27} \mathrm{H}_{29} \mathrm{~N}_{3} \mathrm{O}_{2} \mathrm{~S}, \quad M=459.59$ crystal dimensions: $0.4 \times 0.2 \times 0.2 \mathrm{~mm}^{3}$, monoclinic, $P 12_{1} / c 1$ space group, unit cell dimensions: $a=11.228(2), b=8.077(2), c=$ 26.434(5) Å, $\alpha=90^{\circ}, \beta=93.70(3)^{\circ}, \gamma=90^{\circ}, V=2392.4(9)$ $\AA^{3}, T=250 \mathrm{~K}, Z=4, \rho_{\text {calcd }}=1.276 \mathrm{~g} \mathrm{~cm}^{-3}$. The structure was refined anisotropically $R_{1}(F)=0.0583$ for observed data $(I>$ $2 \sigma(I)$ ), final $R$ values (all data) $R_{1}(F)=0.0866, \mathrm{w} R_{2}(F)=$ 0.1323 for all data.

Crystal data for 6. Explanation to checkcifs: The crystal diffracts poorly and some reflexions are weak and missing. Because of the theta-full value is slightly lower than 0.95 .

Mesomorphic Properties. The optical textures of the mesophases were studied with an Olympus polarizing microscope BX51 equipped with a Linkam hot-stage and Linkam TMS 91 central processor. The transition temperatures and enthalpies were measured by differential scanning calorimetry with a TA Instruments Q20 instrument operated at a scanning rate of $10{ }^{\circ} \mathrm{C} \mathrm{min}^{-1}$ on both heating and cooling. The apparatus was calibrated with indium $\left(156.6^{\circ} \mathrm{C} ; 28.71 \mathrm{~J}\right.$ $\mathrm{g}^{-1}$ ) as the standard. The thermogravimetric analysis (TGA) was carried out in a TGA-Q5000 apparatus at a heating rate of $10^{\circ} \mathrm{min}^{-1}$ under nitrogen up to $600^{\circ} \mathrm{C}$ and under air from 600 to $750{ }^{\circ} \mathrm{C}$. The XRD patterns at the mesophases were obtained with a pinhole camera (Anton-Paar) operating with a pointfocused Ni-filtered $\mathrm{Cu} \mathrm{K} \alpha$ beam. The sample was held in Lindemann glass capillary ( $1 \mathrm{~mm}$ diameter) and heated, when necessary, in a variable-temperature oven. The capillary axis is perpendicular to the X-ray beam and the pattern is collected on flat photographic film perpendicular to the X-ray beam. Spacing was obtained via Bragg's law.
Linear Spectroscopy. The UV-vis studies were carried out on a PrekinElmer Lambda XLS+ spectrometer. The fluorescence spectra were recorded on an Aminco SLM 8000 spectrophotometer.

Electrochemistry. Cyclic voltammetry (CV) experiments were performed on a Bioanalytical System Inc. (BASI) Epsilon electrochemical workstation in a three-electrode cell at room temperature under nitrogen atmosphere. Electrochemical measurements were carried out in dichloromethane solutions $\left(c=1 \times 10^{-3} \mathrm{M}\right)$ containing $0.1 \mathrm{M}$ tetra- $n$-butylammonium hexafluorophosphate $\left(\mathrm{TBAPF}_{6}\right)$ of supporting electrolyte at a scan rate $100 \mathrm{mV} \mathrm{s}^{-1}$. A three-electrode setup was used, including a platinum working electrode, a $\mathrm{Ag} / \mathrm{AgCl}$ (3 M $\mathrm{NaCl}$ ) reference electrode, and a platinum wire auxiliary electrode. Ferrocene was used as an internal standard, and all potentials were referenced to the ferrocene/ferrocenium redox couple.

\section{ASSOCIATED CONTENT}

\section{Supporting Information}

The Supporting Information is available free of charge on the ACS Publications website at DOI: 10.1021/acsomega.8b01696.

Copy of the ${ }^{1} \mathrm{H}$ NMR and ${ }^{13} \mathrm{C}$ NMR spectra of compounds 2-7, mesomorphic properties of compounds 3-6, linear spectroscopy: UV-vis and fluorescence studies of compounds 3-7 (PDF)

\section{AUTHOR INFORMATION}

\section{Corresponding Author}

*E-mail: bgl@icmm.csic.es. Tel: 913349031. Fax: (+34) 913720623.

ORCID $\odot$

Alberto Concellón: 0000-0002-8932-9085

José L. Serrano: 0000-0001-9866-6633

Berta Gómez-Lor: 0000-0002-2995-9624

Notes

The authors declare no competing financial interest.

\section{ACKNOWLEDGMENTS}

This work was funded by the Spanish Government MINECO CTQ2016-78557-R grant and the Comunidad de Madrid S2013/MIT-2740 (PHAMA_2.0).

\section{REFERENCES}

(1) Klauk, H. Organic Electronics: Materials, Manufacturing and Applications; Wiley- VCH: Weinheim, 2006.

(2) Klauk, H. Organic Electronics: More Materials and Applications; Wiley- VCH: Weinheim, 2012.

(3) Ostroverkhova, O. Organic Optoelectronic Materials: Mechanisms and Applications. Chem. Rev. 2016, 116, 13279-13412.

(4) Stupp, S. I.; Palmer, L. C. Supramolecular Chemistry and SelfAssembly in Organic Materials Design. Chem. Mater. 2014, 26, 507518.

(5) Fleischmann, E.-K.; Zentel, R. Liquid-Crystalline Ordering as a Concept in Materials Science: From Semiconductors to StimuliResponsive Devices. Angew. Chem., Int. Ed. 2013, 52, 8810-8827.

(6) O’Neill, M.; Kelly, S. M. Liquid Crystals for Charge Transport, Luminescence, and Photonics. Adv. Mater. 2003, 15, 1135-1146.

(7) Collings, P. J.; Hird, M. Introduction to Liquid Crystals: Chemistry and Physics; Taylor \& Francis, 1997. 
(8) Sergeyev, S.; Pisula, W.; Geerts, Y. H. Discotic Liquid Crystals: A New Generation of Organic Semiconductors. Chem. Soc. Rev. 2007, 36, 1902-1929.

(9) Kaafarani, B. R. Discotic Liquid Crystals for Opto-Electronic Applications. Chem. Mater. 2011, 23, 378-396.

(10) Ruiz, C.; García Frutos, E.; Hennrich, G.; Gómez Lor, B. Organic Semiconductors toward Electronic Devices: High Mobility and Easy Processability. J. Phys. Chem. Lett. 2012, 3, 1428-1436.

(11) Wöhrle, T.; Wurzbach, I.; Kirres, J.; Kostidou, A.; Kapernaum, N.; Litterscheidt, J.; Haenle, J. C.; Staffeld, P.; Baro, A.; Giesselmann, F.; Laschat, S. Discotic Liquid Crystals. Chem. Rev. 2016, 116, 11391241.

(12) Benito-Hernández, A.; Pandey, U. K.; Cavero, E.; Termine, R.; García-Frutos, E. M.; Serrano, J. L.; Golemme, A.; Gómez-Lor, B. High Hole Mobility in Triindole-Based Columnar phases: Removing the Bottleneck of Homogeneous Macroscopic Orientation. Chem. Mater. 2013, 25, 117-121.

(13) García-Frutos, E. M.; Pandey, U. K.; Termine, R.; Omenat, A.; Barberá, J.; Serrano, J. L.; Golemme, A.; Gómez-Lor, B. High Charge Mobility in Discotic Liquid-Crystalline Triindoles: Just a Core Business? Angew. Chem., Int. Ed. 2011, 50, 7399-7402.

(14) An, Z.; Yu, J.; Domercq, B.; Jones, S. C.; Barlow, S.; Kippelen, B.; Marder, S. R. Room-temperature discotic liquid-crystalline coronene diimides exhibiting high charge-carrier mobility in air. J. Mater. Chem. 2009, 19, 6688-6698.

(15) Gómez-Esteban, S.; Benito-Hernandez, A.; Termine, R.; Hennrich, G.; Navarrete, J. T. L.; Ruiz Delgado, M. C.; Golemme, A.; Gómez-Lor, B. High-Mobility Self-Assembling Truxenone-Based n-Type Organic Semiconductors. Chem. - Eur. J. 2018, 24, 35763583.

(16) Mobilities which may differ several orders of magnitude are usually encountered when compared mobility values with different alignment requirements: Ruiz, C.; Pandey, U. K.; Termine, R.; GarcíaFrutos, E. M.; López-Espejo, G.; Ortiz, R. P.; Huang, W.; Marks, T. J.; Facchetti, A.; Ruiz Delgado, M. C.; Golemme, A.; Gómez-Lor, B. Mobility versus Alignment of a Semiconducting $\pi$-Extended Discotic Liquid-Crystalline Triindole. ACS Appl. Mater. Interfaces 2016, 8, 26964-26971.

(17) Eccher, J.; Zajaczkowski, W.; Faria, G. C.; Bock, H.; von Seggern, H.; Pisula, W.; Bechtold, I. H. Thermal Evaporation versus Spin-Coating: Electrical Performance in Columnar Liquid Crystal OLEDs. ACS Appl. Mater. Interfaces 2015, 7, 16374-16381.

(18) Shklyarevskiy, I. O.; Jonkheijm, P.; Stutzmann, N.; Wasserberg, D.; Wondergem, H. J.; Christianen, P. C. M.; Schenning, A. P. H. J.; de Leeuw, D. M.; Tomović, Ž.; Wu, J.; Müllen, K.; Maan, J. C. High Anisotropy of the Field-Effect Transistor Mobility in Magnetically Aligned Discotic Liquid-Crystalline Semiconductors. J. Am. Chem. Soc. 2005, 127, 16233-16237.

(19) Iino, H.; Hanna, Ji Availability of Liquid Crystallinity in Solution Processing for Polycrystalline Thin Films. Adv. Mater. 2011, 23, 1748-1751.

(20) Iino, H.; Usui, T.; Hanna, J. I. Liquid crystals for organic thinfilm transistors. Nat. Commun. 2015, 6, No. 6828.

(21) Yaowu, H.; Melda, S.; Dongwei, Z.; Aiyuan, L.; Lijia, Y.; Hongtao, Y.; Chao, H.; Osamu, G.; Yueh-Lin, L.; Hong, M. High Performance OTFTs Fabricated Using a Calamitic Liquid Crystalline Material of 2-(4-Dodecyl phenyl)[1]benzothieno[3,2-b][1]benzothiophene. Adv. Electron. Mater. 2016, 2, No. 1600179.

(22) He, K.; Li, W.; Tian, H.; Zhang, J.; Yan, D.; Geng, Y.; Wang, F. Asymmetric Conjugated Molecules Based on [1]Benzothieno[3,2-b] [1]benzothiophene for High-Mobility Organic Thin-Film Transistors: Influence of Alkyl Chain Length. ACS Appl. Mater. Interfaces 2017, 9, 35427-35436.

(23) Sonar, P.; Singh, S. P.; Sudhakar, S.; Dodabalapur, A.; Sellinger, A. High-Mobility Organic Thin Film Transistors Based on Benzothiadiazole-Sandwiched Dihexylquaterthiophenes. Chem. Mater. 2008, 20, 3184-3190.

(24) Sonar, P.; Singh, S. P.; Leclere, P.; Surin, M.; Lazzaroni, R.; Lin, T. T.; Dodabalapur, A.; Sellinger, A. Synthesis, characterization and comparative study of thiophene-benzothiadiazole based donoracceptor-donor (D-A-D) materials. J. Mater. Chem. 2009, 19, $3228-3237$

(25) Du, J.; Biewer, M. C.; Stefan, M. C. Benzothiadiazole building units in solution-processable small molecules for organic photovoltaics. J. Mater. Chem. A 2016, 4, 15771-15787.

(26) Findlay, N. J.; Breig, B.; Forbes, C.; Inigo, A. R.; Kanibolotsky, A. L.; Skabara, P. J. High brightness solution-processed OLEDs employing linear, small molecule emitters. J. Mater. Chem. C 2016, 4, $3774-3780$

(27) Aguiar, L. d. O.; Regis, E.; Tuzimoto, P.; Girotto, E.; Bechtold, I. H.; Gallardo, H.; Vieira, A. A. Investigation of thermal and luminescent properties in 4,7-diphenylethynyl-2,1,3-benzothiadiazole systems. Liq. Cryst. 2018, 45, 49-58.

(28) Zhang, X.; Yamaguchi, R.; Moriyama, K.; Kadowaki, M.; Kobayashi, T.; Ishi-i, T.; Thiemann, T.; Mataka, S. Highly dichroic benzo-2,1,3-thiadiazole dyes containing five linearly [small pi]conjugated aromatic residues, with fluorescent emission ranging from green to red, in a liquid crystal guest-host system. J. Mater. Chem. 2006, 16, 736-740.

(29) Dunmur, D. A. The magic of cyanobiphenyls: celebrity molecules. Liq. Cryst. 2015, 42, 678-687.

(30) Gray, G. W.; Lydon, J. E. New type of smectic mesophase? Nature 1974, 252, 221.

(31) Paterson, D. A.; Abberley, J. P.; Harrison, W. T. A.; Storey, J. M. D.; Imrie, C. T. Cyanobiphenyl-based liquid crystal dimers and the twist-bend nematic phase. Liq. Cryst. 2017, 44, 127-146.

(32) Huitorel, B.; Benito, Q.; Fargues, A.; Garcia, A.; Gacoin, T.; Boilot, J.-P.; Perruchas, S.; Camerel, F. Mechanochromic Luminescence and Liquid Crystallinity of Molecular Copper Clusters. Chem. Mater. 2016, 28, 8190-8200.

(33) Sadati, M.; Ramezani-Dakhel, H.; Bu, W.; Sevgen, E.; Liang, Z.; Erol, C.; Rahimi, M.; Taheri Qazvini, N.; Lin, B.; Abbott, N. L.; Roux, B.; Schlossman, M. L.; de Pablo, J. J. Molecular Structure of Canonical Liquid Crystal Interfaces. J. Am. Chem. Soc. 2017, 139, 3841-3850.

(34) Prabhu, R.; Yelamaggad, C. V. Structure-Property Correlations in Cyanobiphenyl-Based Dimer-Like Mesogens. J. Phys. Chem. B 2015, 119, 11935-11952.

(35) Kim, Y.-K.; Wang, X.; Mondkar, P.; Bukusoglu, E.; Abbott, N. L. Self-reporting and self-regulating liquid crystals. Nature 2018, 557, 539-544.

(36) Grabowski, Z. R.; Rotkiewicz, K.; Rettig, W. Structural Changes Accompanying Intramolecular Electron Transfer: Focus on Twisted Intramolecular Charge-Transfer States and Structures. Chem. Rev. 2003, 103, 3899-4032.

(37) Dolomanov, O. V.; Bourhis, L. J.; Gildea, R. J.; Howard, J. A. K.; Puschmann, H. OLEX2: a complete structure solution, refinement and analysis program. J. Appl. Crystallogr. 2009, 42, 339-341. 